\title{
Upper mantle structure beneath the Azores hotspot from finite-frequency seismic tomography
}

\author{
Ting Yang ${ }^{a, *}$, Yang Shen ${ }^{a}$, Suzan van der Lee ${ }^{b}$, \\ Sean C. Solomon ${ }^{c}$, Shu-Huei Hung ${ }^{d}$ \\ ${ }^{a}$ Graduate School of Oceanography, University of Rhode Island, Narragansett, RI 02882, USA \\ ${ }^{\mathrm{b}}$ Department of Geological Sciences, Northwestern University, Evanston, IL 60208, USA \\ ${ }^{c}$ Department of Terrestrial Magnetism, Carnegie Institution of Washington, Washington, DC 20015, USA \\ d Department of Geosciences, National Taiwan University, Taipei, Taiwan
}

Received 6 February 2006; received in revised form 13 July 2006; accepted 14 July 2006

Available online 28 August 2006

Editor: S. King

\begin{abstract}
The Azores archipelago is a classic expression of a hotspot that has interacted with a mid-ocean ridge. A variety of geochemical studies and geophysical observations point to the influence of some sort of mantle plume on the formation of the Azores Plateau and the adjacent Mid-Atlantic Ridge (MAR), but the mantle structure beneath the Azores has not heretofore been imaged tomographically at a sufficiently fine resolution to resolve a narrow plume. We present a $P$-wave velocity model of the mantle beneath the hotspot derived from teleseismic body waves recorded by six broadband seismic stations on the Azores Islands including the Global Seismographic Network station CMLA. Three-dimensional travel-time sensitivity kernels are used to account for the effects of wavefront healing and scattering of seismic waves. An inversion of $228 P$-wave travel-time delays reveal a lowvelocity anomaly in the shallow mantle (less than $200 \mathrm{~km}$ deep) along the Azores archipelago and beneath the Azores Plateau (centered approximately at $38.5^{\circ} \mathrm{N}, 28.5^{\circ} \mathrm{W}$ ). The low-velocity anomaly extends northeastward and downward to connect to a plume-like column of low-velocity material from $\sim 250 \mathrm{~km}$ to at least $400 \mathrm{~km}$ depth centered northeast of Terceira. These results are consistent with other geophysical and geochemical observations and provide seismic evidence for a model of plume-ridge interaction in which the plume conduit is deflected to the southwest in the shallow mantle by asthenospheric flow and plate motion and contributes hot mantle material and excess melt to the MAR south of the Azores.
\end{abstract}

(C) 2006 Elsevier B.V. All rights reserved.

Keywords: Azores; Mid-Atlantic Ridge; hotspot; mantle plume; triple junction; plume-ridge interaction; finite-frequency tomography

\section{Introduction}

The Azores archipelago, located near the triple junction of the North American, African, and Eurasian

\footnotetext{
* Corresponding author. Now at Department of Geological Sciences, The University of Texas at Austin, USA.

E-mail address: tyang@mail.utexas.edu (T. Yang).
}

plates, represents a classic example of the surface expression of a hotspot that has interacted with a midocean ridge. During the past three decades, a variety of efforts have been made to understand the dynamic processes responsible for the formation of the Azores Plateau and the evolution of the plate triple junction. Geochemical constraints from basalts collected on the islands and along the nearby Mid-Atlantic Ridge (MAR) 
(e.g., [1-5]) and a variety of geophysical observations including topography and gravity [6-8] and magnetic anomalies $[9,10]$ have provided evidence for the influence of a possible mantle plume on the characteristics of the Azores Plateau and nearby segments of the MAR, but no seismic tomographic study to date has resolved a plume-like low-velocity anomaly beneath the plateau. Global tomographic (e.g., $[11,12])$ and regional seismic velocity models [13-16] show a broad lowvelocity anomaly beneath or near the Azores Plateau. The horizontal resolution in these studies, however, has been too coarse to identify a narrow feature such as a mantle plume, constrained on fluid dynamical grounds to have a diameter in the upper mantle of a few hundred kilometers or less [17]. The low-velocity anomaly in the upper mantle beneath Iceland, for example, has a diameter of $200-300 \mathrm{~km}$ [18-21]. Consequently, the nature of the Azores hotspot including its source location, depth of origin, and interaction with the MAR and the triple junction remain enigmatic.

In this study, we use broadband seismic data collected on the Azores Islands and the newly developed finite-frequency seismic tomography method for regional seismic networks [21,22] to construct the first regional-scale $P$-velocity model of the upper mantle beneath the Azores. Our results provide new constraints on the dynamic processes that have formed the archipelago.

\section{Data and methodology}

\subsection{Data}

The data used in this study are from the COSEA (COordinated Seismic Experiment in the Azores) experiment [23], which consisted of four temporary broadband stations deployed along the Azores Islands from December 2000 to September 2002 as well as two permanent stations CMLA and CDRO (Fig. 1 and Table 1). Because of the limited dimensions and nearly linear distribution of the islands in the Azores archipelago, the seismic network had a limited aperture, particularly in the north-south direction. The data were also affected by relatively high ocean-generated noise, especially on the horizontal com-

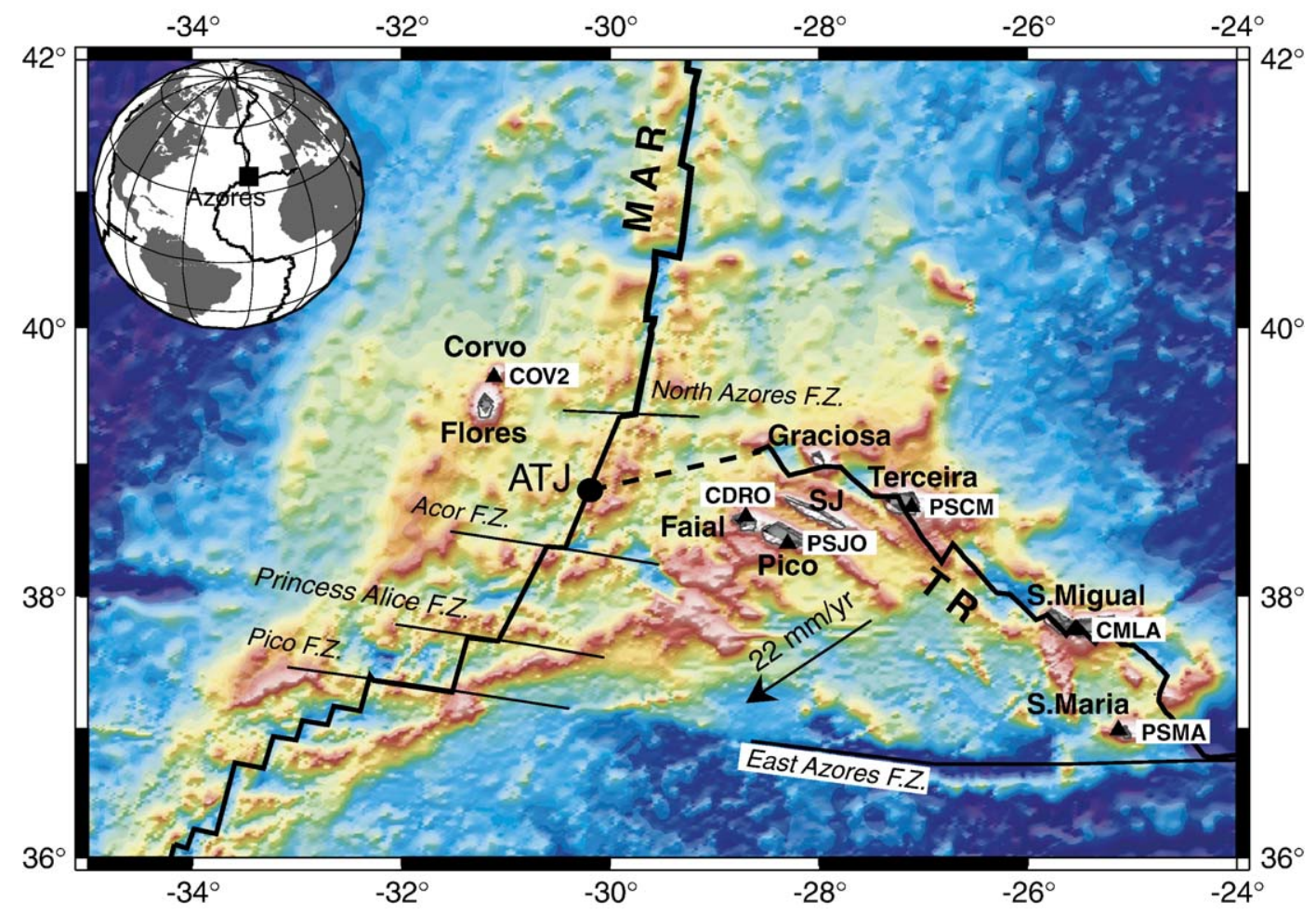

Fig. 1. Map of the Azores archipelago and adjacent region, showing all nine islands (western group: Flores and Corvo; central group: Terceira, Graciosa, Sao Jorge (SJ), Pico, and Faial; eastern group: Sao Miguel, and Santa Maria); the geological setting — Mid-Atlantic Ridge (MAR), Terceira Rift (TR), fracture zones, and the proposed Azores triple junction (ATJ, solid circle) $[9,10]$; the absolute plate motion direction of the African and Eurasian plates relative to a hotspot reference frame (arrow) [53]; and the seismic stations used in this study (solid triangles). The dashed line shows the uncertain location of the African-Eurasian plate boundary near the MAR. 
Table 1

Station information for the COSEA seismic experiment

\begin{tabular}{lllllrr}
\hline Station name & Start time & End time & $\begin{array}{l}\text { Latitude } \\
\left({ }^{\circ} \mathrm{N}\right)\end{array}$ & $\begin{array}{l}\text { Longitude } \\
\left({ }^{\circ} \mathrm{W}\right)\end{array}$ & $\begin{array}{l}\text { Elevation } \\
(\mathrm{m})\end{array}$ & $\begin{array}{l}\text { Station term } \\
(\mathrm{s})\end{array}$ \\
\hline CMLA & - & - & 37.7637 & 25.5243 & 429 & 0.0994 \\
CDRO & $2001-07-03$ & - & 38.6292 & 28.6292 & 195 & 0.0608 \\
COV2 & $2001-05-15$ & $2002-09-13$ & 39.6772 & 31.1133 & 2794 & -0.1947 \\
PSCM & $2000-12-06$ & $2002-09-06$ & 38.7008 & 27.1166 & 400 & 0.1155 \\
PSJO & $2000-12-08$ & $2002-09-05$ & 38.4215 & 28.3033 & 258 & 0.0775 \\
PSMA & $2000-12-15$ & $2002-09-18$ & 36.9957 & 25.1308 & 249 & -0.1586 \\
\hline
\end{tabular}

ponents. After inspecting all waveforms, we decided to limit our analyses to compressional arrivals and to studies of the $P$-wave velocity beneath the region.

We filtered $P$-waves on the vertical component into high-, intermediate-, and low-frequency bands $(0.5-2.0$, $0.1-0.5$ and $0.03-0.1 \mathrm{~Hz}$, respectively). A threshold value of signal-to-noise ratio (20) was specified for automated data selection in each frequency band, and each selected record was inspected visually for consistency. The signal-to-noise ratio is defined as the ratio of the peak-to-peak amplitude of the main arrival to the standard deviation of the time series in an 80 -s window before the main arrival. With such a criterion, we selected 41 teleseismic earthquakes from 992 events with body- or surface-wave magnitude greater than 5.5 between December 1, 2000, and December 31, 2002. Fig. 2 shows the distribution of the earthquakes used in this study. We obtained 228 high-quality $P$-wave

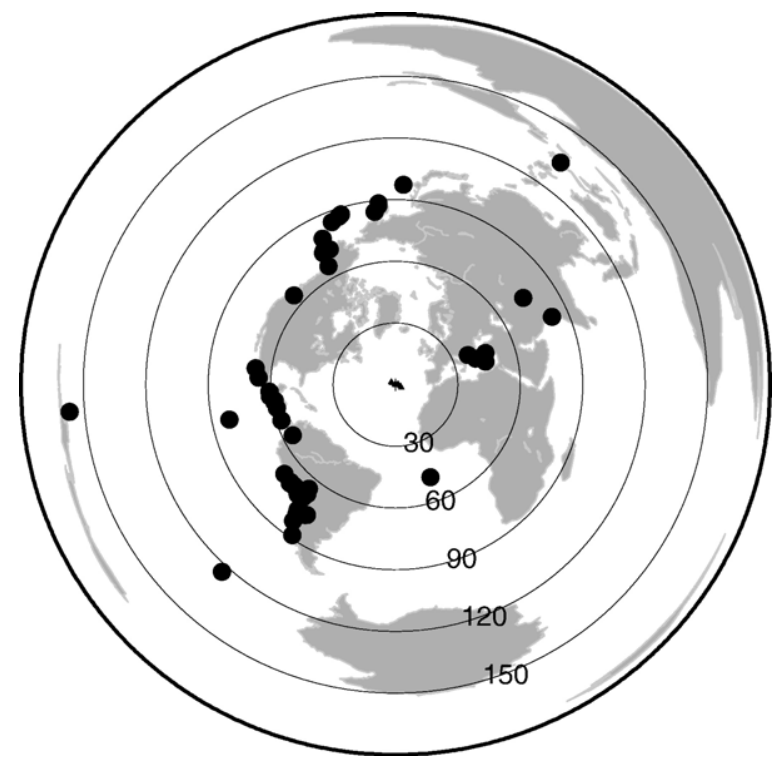

Fig. 2. Distribution of earthquakes from which $P$-wave arrivals were used in the inversion (azimuthal equidistant projection centered at $\left.38.5^{\circ} \mathrm{N}, 28.5^{\circ} \mathrm{W}\right)$. arrivals, including 11 PKPdf phase arrivals. Most of the selected waveforms are long-period records with frequencies $(0.03-0.1 \mathrm{~Hz})$ in the notch of the background oceanic noise spectrum [24]. Only 66 carefully selected high- and intermediate-frequency band records are included in the inversion.

The relative travel-time delays of the arrivals were measured by the multi-channel cross-correlation (MCCC) method [25] in each frequency band for each event. The resulting data set of relative travel times is of high accuracy, with the mean value of the standard deviations obtained from MCCC being $35 \mathrm{~ms}$. For comparison, the estimated standard deviations for $P$ wave delays in the (high-frequency) Iceland data set are approximately $30 \mathrm{~ms}$ [18].

\subsection{Finite-frequency seismic tomography}

Global and regional tomographic studies utilizing seismic travel times usually make use of ray theory (e.g., [26-30]), which is based on the assumptions that seismic waves have infinite frequency and the arrival time of a body wave depends only on the velocity along the geometrical ray path between the source and receiver. Seismic waves, however, are finite-frequency signals, their travel times are sensitive to a threedimensional (3-D) volume around the wave path, and they are subject to scattering and diffraction. As a result, seismic waves passing through velocity heterogeneities with dimensions smaller than the width of the Fresnel zone undergo significant wavefront healing, which results in reduced travel-time shifts compared with the predictions of ray theory [31-33]. Tomography based on ray theory, therefore, tends to underestimate the magnitude of velocity heterogeneities [21].

The 3-D Fréchet travel-time sensitivity kernels [3436] of finite-frequency seismic tomography (FFST) enable us to account for wavefront healing and off-ray scattering. Because seismic waves with different frequency contents sample different volumes of the velocity structure [21,32,37], the relative travel-time 
delays are frequency dependent. An example of the relative travel-time delays in three frequency bands is shown in Fig. 3 for four stations used in our study. The relative delays of low-frequency $P$-waves are significantly smaller than those of higher frequency arrivals, suggesting that wave diffraction takes place as the finitefrequency waves propagate and the low-frequency travel-time delays are reduced because of their broader kernels and larger "doughnut holes" of relatively weak sensitivity [38].
With the availability of digital seismic records, the MCCC method [25] has been used in many regional and global tomographic studies to measure travel-time shifts. Such measurements tend to be more accurate than handpicked or automated phase picks (e.g., International Seismological Centre travel times). Furthermore, with the finite-frequency sensitivity kernels, we may combine the measured travel-time delays at all available frequencies, fully utilizing the broadband nature of observed seismic waves. This
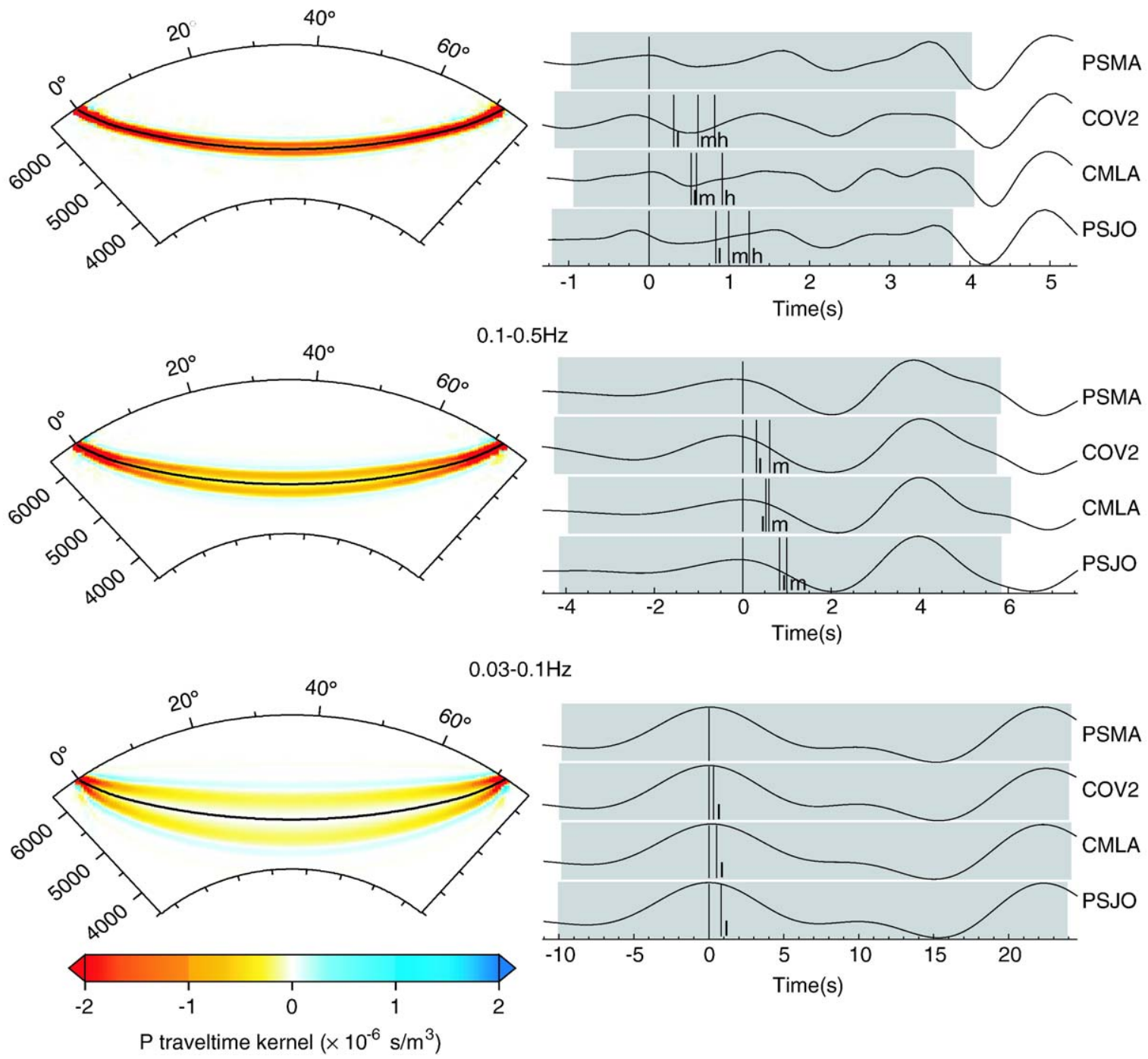

Fig. 3. (Left) Comparison of Born-Fréchet kernels for the travel times of teleseismic $\mathrm{P}$ phases, measured by cross-correlation of the observed waveforms with the synthetics in the three frequency bands $0.5-2.0,0.1-0.5$, and $0.03-0.1 \mathrm{~Hz}$. (Right) Examples of frequency-dependent $P$-wave relative travel time delays observed at Azores stations from the Peru earthquake of 23 June $2001\left(m_{\mathrm{b}}=5.9\right)$. Broadband signals have been band-pass filtered from (top) 0.5 to $2.0 \mathrm{~Hz}$ to measure high-frequency relative travel time delays ("h"), (middle) 0.1 to $0.5 \mathrm{~Hz}$ for intermediate-frequency measurement ("m"), and (bottom) 0.03 to $0.1 \mathrm{~Hz}$ for low-frequency measurement ("l"). The waveforms are aligned according to the time picks of the multi-channel cross-correlation (MCCC) method [25]. Shaded portions of seismograms indicate the windows for cross-correlation. 
"data fusion" is justifiable because travel-time delays in different frequency ranges sample different 3-D volumes. The ability to integrate travel times in different frequencies is particularly important in oceanic settings, where good-quality seismic arrivals are far more frequently recorded in the long-period band (10-33 s) than at higher frequencies because of microseisms in the oceanic environment [24]. In contrast, under ray theory travel-time delays are invariably attributed to velocity heterogeneity along the wave path, no matter what frequencies are used to determine the arrival times. Thus the relative delays obtained in different frequency bands have to be solved separately under a ray approximation for velocity perturbations [20]. The 3-D kernel theory has been applied to regional [21,22] and global [12] seismic tomography. A comparison of the kernel-and ray-based velocity models beneath Iceland showed that finite-frequency tomography utilizing fully broadband signals significantly improves the resolution of the velocity structure beneath the Iceland hotspot [21].

In this study, we follow the general methodology and data-processing procedure described by Hung et al. [21]. Here we highlight the main differences between this new method and the traditional ray-based seismic tomography.

The general formula for the inverse problem, after parameterization of the model function on a spatial grid of nodes, can be expressed in a concise matrix form for a discrete inverse problem:

$\mathbf{d}_{i}=\mathbf{A}_{i l} \mathbf{m}_{l}$

For teleseismic regional tomography, $\mathbf{d}_{i}$ represents the $i$ th relative travel time delay, and $\mathbf{m}_{l}$ is the velocity perturbation at the $l$ th grid node. The difference between ray-based and kernel-based tomography is in $\mathbf{A}_{i l}$. In traditional ray-based tomography, $\mathbf{A}_{i l}$ is the difference in the total path lengths through a specific volume that contributes to the $l$ th model node between the two arrivals in the $i$ th paired relative travel-time measurement. In the 3-D kernel-based inverse problem, however, $\mathbf{A}_{i l}$ is the differential value of the integrated volumetric kernels contributing to the $l$ th node [21]. In order to make the sparse equation solvable, a smoothness regularization is usually needed in the ray-based inversion problem, whereas in FFST the 3-D BornFréchet kernel provides a smoothness constraint directly through the matrix A. Simple norm damping is applied in FFST to avoid more ad hoc smoothness enforcement [39].

\subsection{Inversion}

The $P$-wave velocity structure beneath the Azores hotspot was parameterized by a 3 -D grid $(33 \times 33 \times 33)$ centered at $38.5^{\circ} \mathrm{N}, 28.5^{\circ} \mathrm{W}$, and with a dimension of $19^{\circ}$ in longitude, $13^{\circ}$ in latitude, and $1200 \mathrm{~km}$ in the vertical direction. The grid spacing is $52 \mathrm{~km}$ in longitude, $45 \mathrm{~km}$ in latitude, and $38 \mathrm{~km}$ in depth.

The inversion of the matrix is approximated by the iterative solution of the LSQR algorithm [40]. In order to determine a damping factor for the inversion, we performed a trade-off analysis of model norm versus variance reduction [41]. The trade-off relation of the model L2 norm versus travel-time variance reduction is shown in Fig. 4 for different damping factors. We selected the damping factor that yields an optimum reduction of the travel-time misfit with a relatively small model norm. With the selected damping factor, the inversion yields a variance reduction of $78 \%$.

Variations in crustal thickness, station elevation, and lateral velocity heterogeneities in the uppermost mantle all contribute to travel-time anomalies. Because the paths of teleseismic waves are nearly vertical in the shallow mantle and crust beneath stations, there are no crossing paths at shallow depths $[42,43]$. Velocity structure at these depths is, therefore, poorly constrained in the inversion. In order to mitigate the possibility of streaking of these shallow variations into the deeper mantle, an additional free term for each station was added to the inversion to absorb travel-time shifts

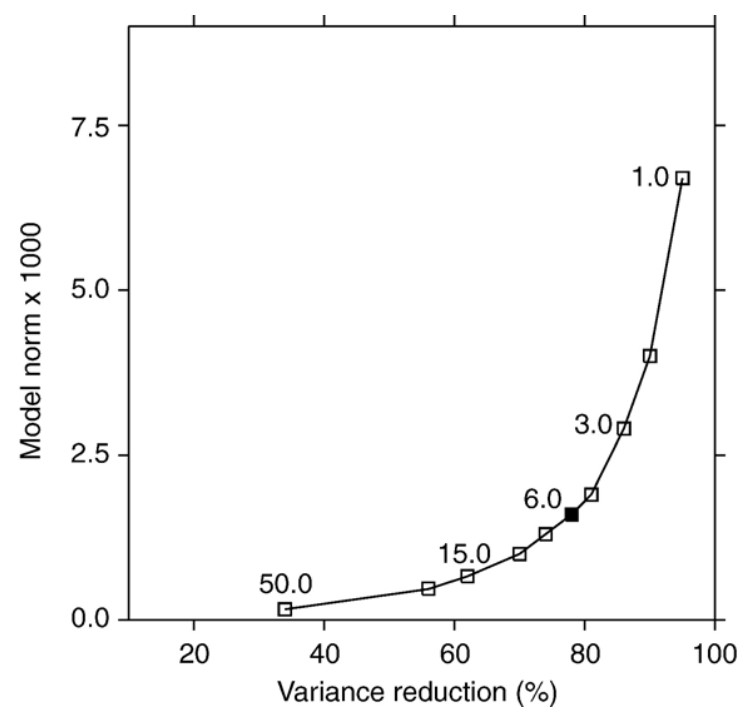

Fig. 4. Trade-off between model norm and variance reduction for different norm damping factors. The solid symbol indicates the damping factor used (6.0) for our final inversion model. 


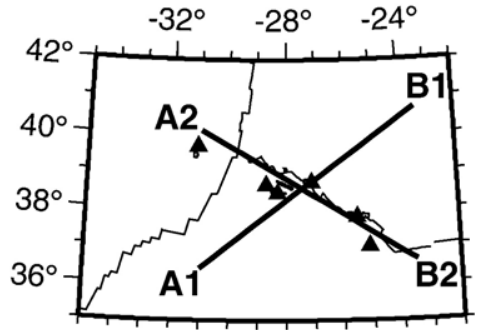

(a)
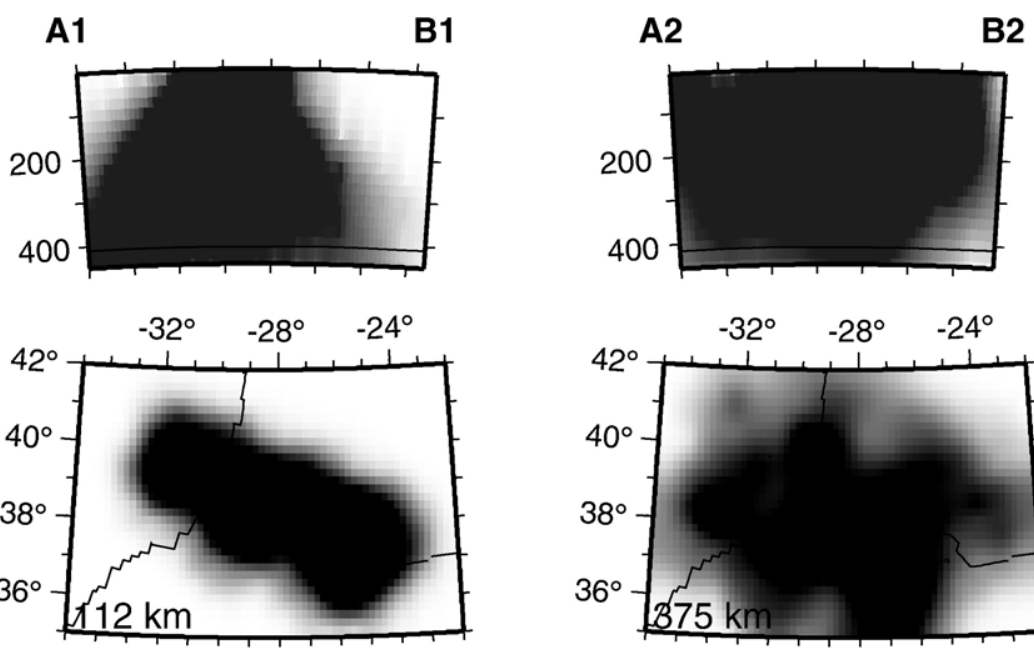

B2

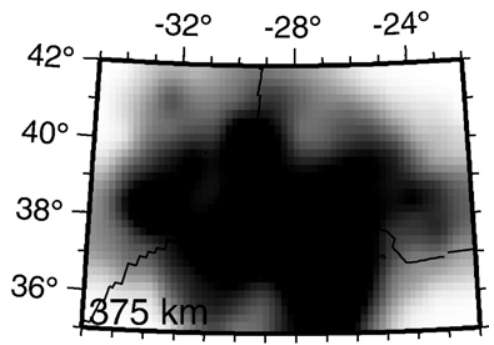

(b)
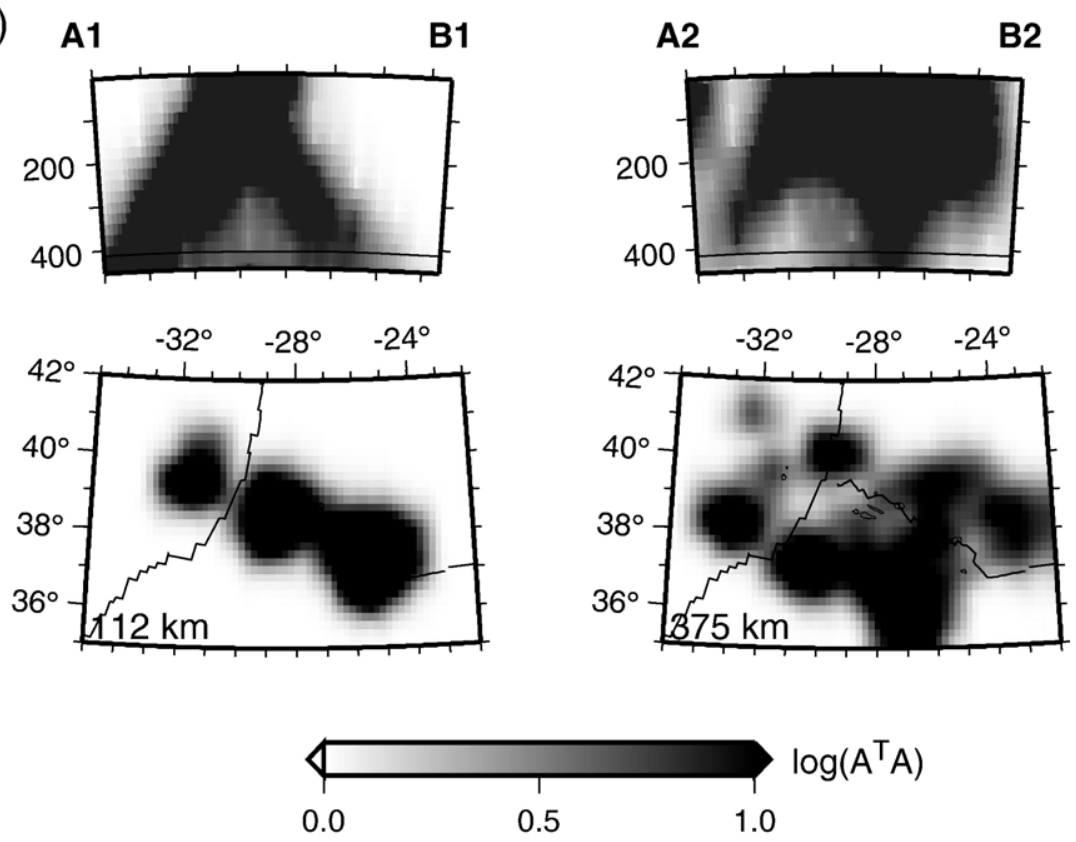

Fig. 5. Sampling of model space by (a) all data and (b) high- and intermediate-frequency data only, as measured by the diagonal elements of the matrix $\mathbf{A}^{T} \mathbf{A}$ in natural logarithm scale, where $\mathbf{A}$ is the Gram matrix for the inversion (Eq. (1)).

caused by variations in shallow structure. As shown in Table 1, our inversion obtained positive station terms (late arrivals) for CDRO, CMLA, PSCM, and PSJO, and negative values (early arrivals) for the stations at the eastern and western ends of the array (COV2 and PSMA, Fig. 1). The maximum difference between the 
station terms is $0.31 \mathrm{~s}$. Subtracting the delays due to variation in station elevation $(<250 \mathrm{~m})$ gives a residual maximum difference of $0.28 \mathrm{~s}$, which approximately matches the maximum travel-time difference expected from variations in crustal thickness across this region $(<10 \mathrm{~km})[44,45]$.

One way to assess the resolution of seismic tomography is to check the sampling of model space by seismic waves from the data set. The sampling density can be represented by the diagonal values of the product of the Gram matrix A (Eq. (1)) and its transpose $\mathbf{A}^{T}$, diag $\left(\mathbf{A}^{T} \mathbf{A}\right)$. The value of each element of $\operatorname{diag}$ $\left(\mathbf{A}^{T} \mathbf{A}\right)$ equals the total sum of the squares of the
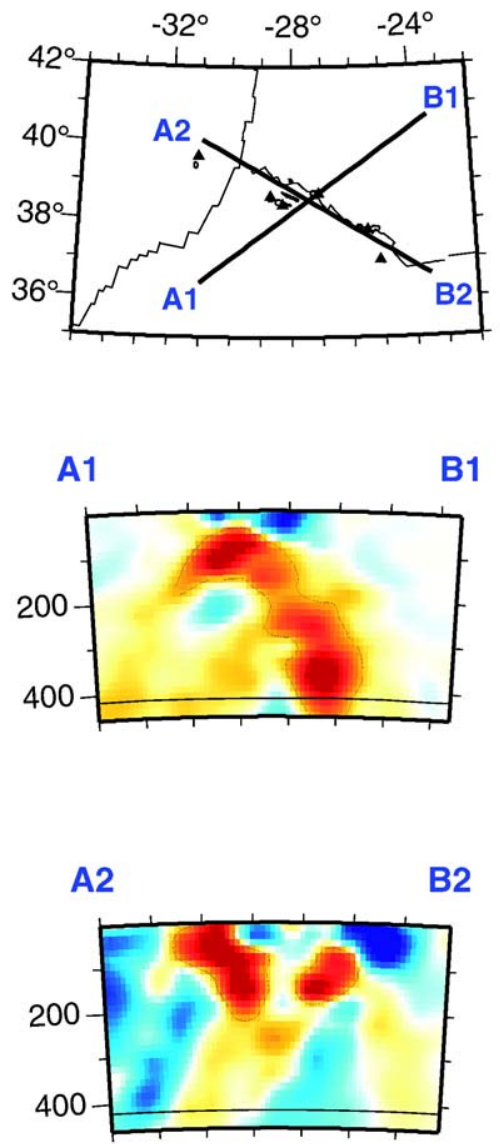

B2 volumetric kernels contributing to each node. The spatial distribution of sampling density for this study is shown in Fig. 5. There are major gaps in sampling the mantle structure beneath the Azores by the high- and intermediate-frequency arrivals. The sampling is much improved when we include the arrivals from the full broadband frequency range, because low-frequency waves are relatively more abundant and their broader kernels fill the gaps between the spaces sampled by the relatively narrower kernels of high- and intermediatefrequency arrivals. As expected from the station distribution, a profile along the Azores Islands has much better sampling than a profile perpendicular to the
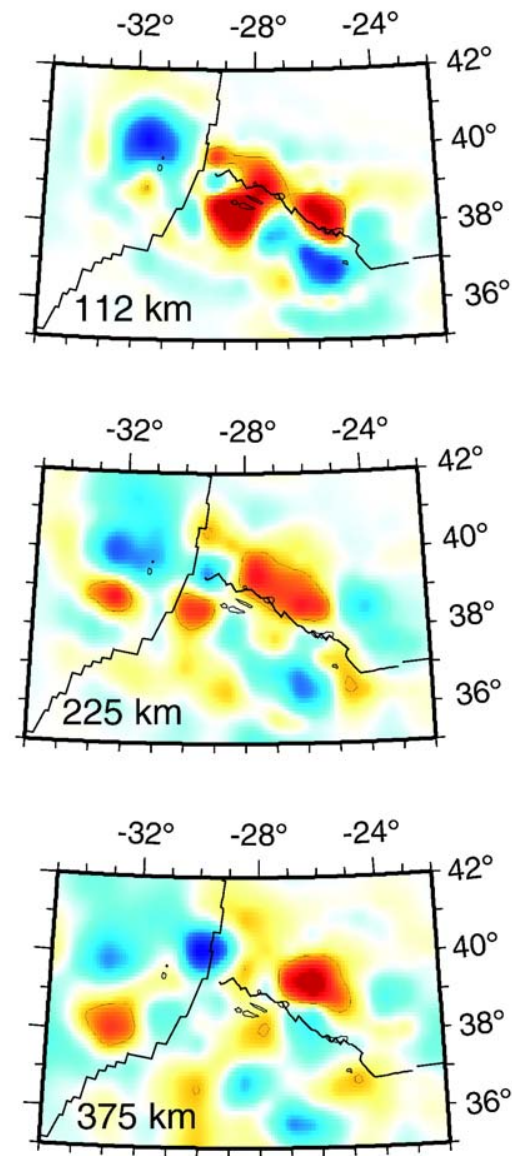

\section{$\mathrm{P}$-wave velocity anomaly (\%)}

Fig. 6. $P$-wave velocity model obtained from finite-frequency tomography using 3-D travel-time sensitivity kernels. Values shown are velocity anomaly relative to the iasp91 reference model [85], plotted on two vertical cross-sections and three horizontal sections at 112,225 , and $375 \mathrm{~km}$ depth. Contours outline regions in which velocities are at least $0.5 \%$ lower than average values for the given depth. The lines in map view delineate the MAR and the Terceira Rift. Heavy lines A1-B1 and A2-B2 mark the locations of the vertical cross-sections. The horizontal lines in the vertical cross-sections denote the $410-\mathrm{km}$ seismic discontinuity. 
(a)
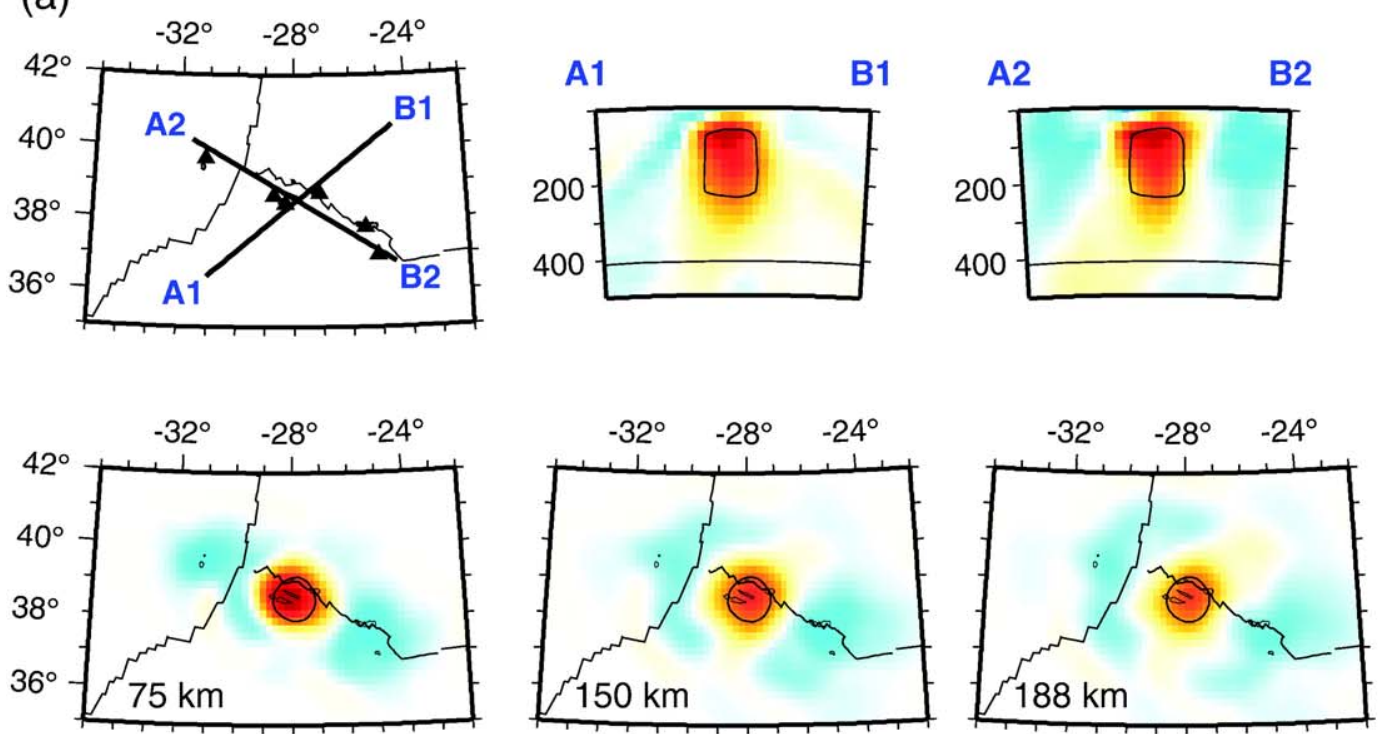

(b)
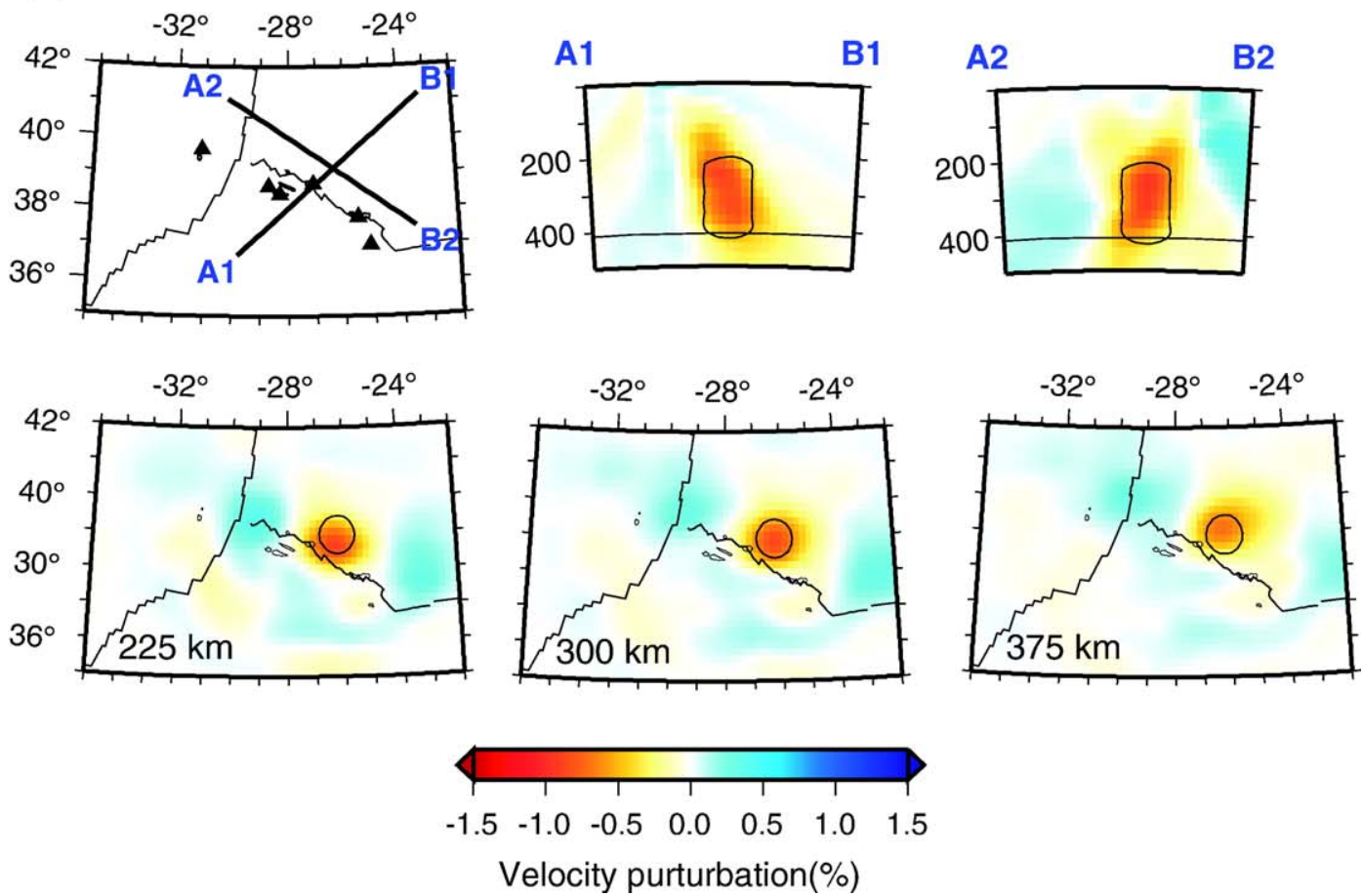

Fig. 7. Resolution tests. The input synthetic velocity anomalies are (a) a low-velocity vertical cylinder with a diameter of $125 \mathrm{~km}$ at a depth range of $75-225 \mathrm{~km}$ beneath the center of the Azores Plateau and (b) a vertical cylinder with a diameter of $100 \mathrm{~km}$ centered northeast of Terceira from $225 \mathrm{~km}$ to $412 \mathrm{~km}$ depth. The magnitude of the input anomaly decays as a Gaussian function from the center of the cylinder, where the peak velocity perturbation is $-4 \%$. The width of the input anomaly is defined as the diameter of the contour at half the maximum velocity anomaly ( $-2 \%)$ in each horizontal section. The mean synthetic travel time delays have been subtracted as with the observed data, so the recovered low-velocity anomaly is flanked by positive velocity perturbations of modest amplitude, an effect that contributes to the fact that the magnitude of the recovered velocity anomaly is less then that of the input model. 
archipelago. Despite the limitations of the data set, the broader sensitivity kernels provide a fairly good coverage to $\sim 400 \mathrm{~km}$ depth.

\section{Results and resolution tests}

The $P$-wave velocity model beneath the Azores obtained from the inversion using the 3-D finitefrequency kernels is shown in Fig. 6. In the uppermost $\sim 200 \mathrm{~km}$ of the mantle, there is a lowvelocity anomaly with a peak magnitude of $-1.5 \%$ elongated along the orientation of the Azores Islands $\left(\mathrm{N} 110^{\circ} \mathrm{E}\right)$. This anomaly merges with a slightly stronger low-velocity anomaly beneath the center of the Azores Plateau and near the proposed location of the triple junction $\left(38.55^{\circ} \mathrm{N}, 30^{\circ} \mathrm{W}\right)$ between the North American, Eurasian, and African plates $[9,10]$. No low-velocity anomaly was resolved beneath the center of the Azores Plateau at depths greater than $250 \mathrm{~km}$. Instead, the shallow low-velocity anomaly appears to continue downward to the northeast to connect with a near vertical low-velocity body centered northeast of the island of Terceira $\left(39^{\circ} \mathrm{N}\right.$, $26^{\circ} \mathrm{W}$ ) and imaged from $\sim 200 \mathrm{~km}$ depth to at least the top of the mantle transition zone. At depths greater than $250 \mathrm{~km}$, the low-velocity anomaly is approximately circular in planform and has a peak magnitude of $-2.0 \%$.

We conducted a series of resolution tests in which synthetic travel times were calculated for a known input anomaly and the same event-station pairs used in the inversion that yielded Fig. 6. Gaussian noise with a standard deviation of $50 \mathrm{~ms}$ was added to the synthetic travel time delays prior to inversion. The first input model was a vertical low-velocity cylinder with a radius comparable to the anomaly we imaged beneath the center of the Azores Plateau $\left(38.5^{\circ} \mathrm{N}, 28.5^{\circ} \mathrm{W}\right)$ from $75 \mathrm{~km}$ to $225 \mathrm{~km}$ depth. The second was a vertical lowvelocity cylinder at $225-412 \mathrm{~km}$ depth centered northeast of Terceira $\left(39^{\circ} \mathrm{N}, 26^{\circ} \mathrm{W}\right)$. Fig. 7 shows the results of the resolution tests for these two input models. Although the magnitude of the input anomalies cannot be fully recovered, the geometry of the velocity perturbations in both cases is well resolved in our inversions with 3-D sensitivity kernels. We conclude that the shallow anomaly is not caused by streaking from a deeper structure, and vice versa. The lateral location of the shallow anomaly is well resolved in all directions. For the deep anomaly, the structure is well resolved in the east-west direction, but there exists notable streaking in the north-south direction due to the limited network aperture in this direction.
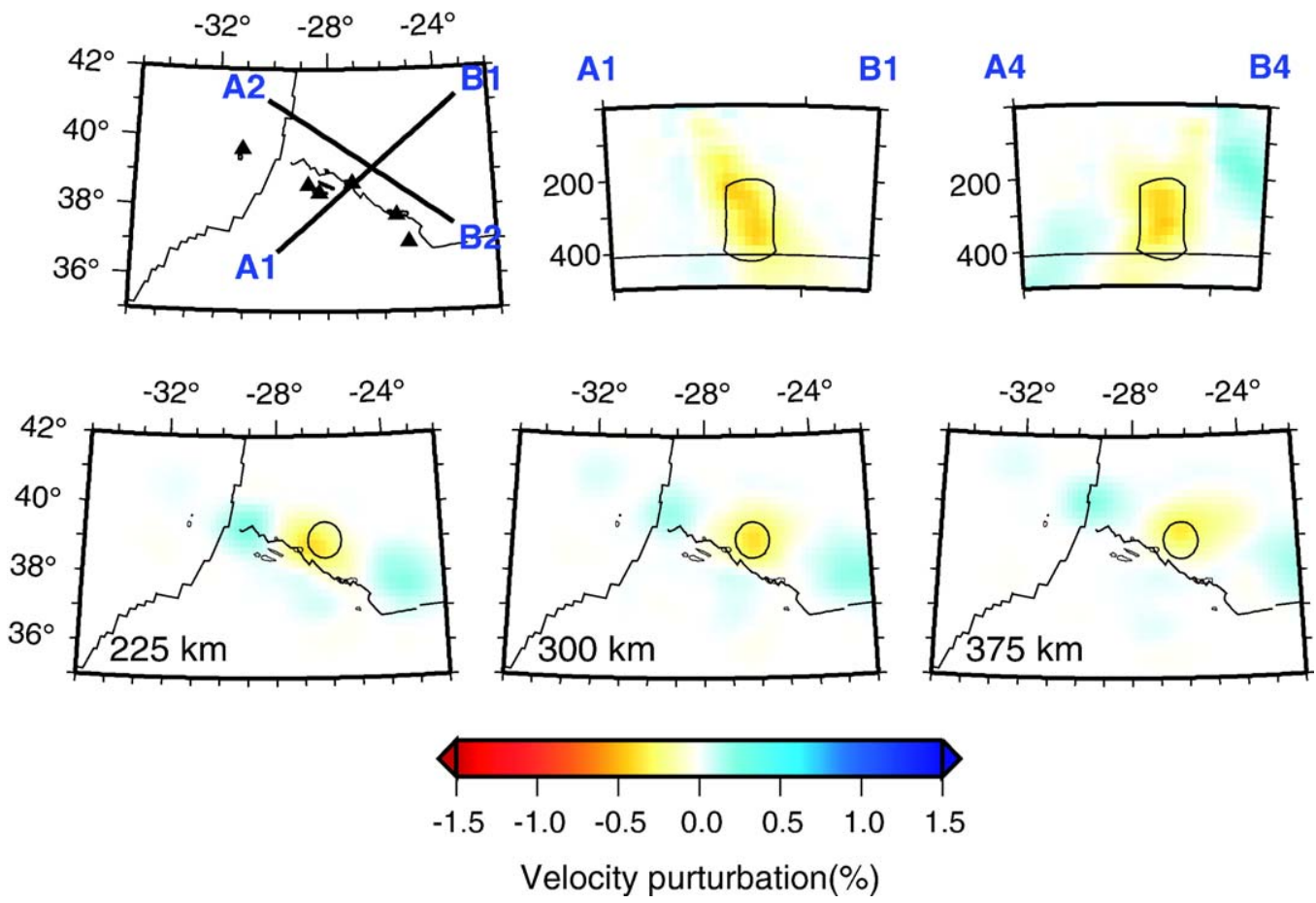

Fig. 8. Resolution tests using only high- and intermediate-frequency data. The input anomaly is the same as that in Fig. 7b. The damping factor was determined from the tradeoff curve of only high- and intermediate-frequency data. 
To test further the apparent bending of the lowvelocity structure and the offset between the shallow and deep anomalies in Fig. 6, we conducted several additional tests. We placed a shallow anomaly immediately above the low-velocity column to the northeast of Terceira and along the Terceira Rift, respectively. The results show that the deep anomaly is not caused by streaking from the shallow mantle. To see whether a deeper mantle source beneath the center of the Azores Plateau is responsible for the formation of the youngest volcanoes (Pico and Sao Jorge) there [46,47], we carried out a resolution test with a vertical low-velocity cylinder at $225-412 \mathrm{~km}$ depth directly beneath this region. Our results show that such an anomaly could be reasonably well resolved by our data set. We conducted similar resolution tests for other regions along the Terceira Rift. These tests indicate that there is no significant lowvelocity anomaly in the deeper portions of the upper mantle beneath the Azores region aside from the one centered to the northeast of Terceira. In particular, the lateral shift of the deep anomaly relative to the shallow anomalies beneath Pico, Faial, and Sao Jorge is required by the data.

In order to understand the contributions from the different frequency bands in our data set, we carried out a test similar to that in Fig. $7 \mathrm{~b}$ but with only high- and intermediate-frequency arrivals. Fig. 8 shows that the resolution with only high-and intermediate-frequency data deteriorates substantially compared with that in Fig. $7 \mathrm{~b}$. The input anomaly was barely detected. In this test, we selected a damping factor on the basis of the tradeoff curve of only high-and intermediate-frequency data, as in Fig. 4. The selected value results in a similar variance reduction $(\sim 80 \%)$. We note that the sensitivity kernels of high- and intermediate-frequency data are more intense and concentrated compared with those of lowfrequency waves. They also differ in the quality of travel-time measurements, so their contributions to the A matrix in Eq. (1) and the influence on the optimum damping factor likely do not scale linearly with the number of travel-time measurements. Furthermore, the two data sets sample somewhat different model spaces. So depending on the location of the input anomaly, the extent of anomaly recovery can be quite different for the different bands.

\section{Discussion}

Our tomographic model shows an approximately columnar low-velocity anomaly centered to the northeast of Terceira and extending downward from $\sim 250 \mathrm{~km}$ at least to the top of the transition zone. In previous large-scale regional seismic tomography studies [13-16] a broad low-velocity anomaly is found on the north side of the Azores Plateau, though the resolution in these studies is typically too coarse to resolve any plume-like structure. In our discussion here and below, the term "plume" is used to denote cylindrical buoyant upwelling originating in the transition zone or deeper and is meant to be distinguished from upwelling driven by melting in the region of primary melt production in the shallow mantle. The cylindrical low-velocity anomaly centered northeast of Terceira is consistent with a mantle plume origin of the Azores hotspot, although the tomographic model does not have resolution deeper than $400 \mathrm{~km}$ to ascertain the source depth of the upwelling implied by the lowvelocity conduit. The available teleseismic arrivals are insufficient to map the transition zone thickness beneath the Azores, as Shen et al. [48] and Li et al. [49] did for Iceland and Hawaii, respectively. A study using records from the GSN station CMLA found a normal average transition zone thickness over a region approximately $450 \mathrm{~km}$ in diameter centered beneath Sao Miguel [50]. Because of the geographic averaging, it is unlikely that such a study would detect a relatively localized transition zone anomaly in the vicinity of the cylindrical low-velocity anomaly to the northeast of Terceira (Fig. 1). On the basis of geochemical measurements of MAR basalts from $30^{\circ}$ to $50^{\circ} \mathrm{N}$, Yu et al. [4] suggested the existence of a plume that bends southward and ridgeward as it rises beneath the eastern flank of the MAR and for which the conduit in the deep mantle may be located as far north as $46^{\circ} \mathrm{N}$. Because of the distribution of seismic stations in the Azores, however, our study cannot constrain whether the low-velocity anomaly imaged from $\sim 250$ to $400 \mathrm{~km}$ may extend northward at greater depth in the mantle.

\subsection{Mantle plume source and migrating ridge sink}

We suggest that the cylindrical low-velocity volume at $250-400 \mathrm{~km}$ depth centered northeast of Terceira, offset $\sim 200 \mathrm{~km}$ from the center of the Azores Plateau, is the source of the Azores hotspot. We suggest further that the bending of the low-velocity anomaly toward the southwest in the shallow mantle is the result of a deflection of plume upwelling by regional upper mantle shear flow. Such deflection has been demonstrated both experimentally and theoretically (e.g., [51,52]). According to an absolute plate motion model [53], the African and Eurasian plates near the Azores have a southwestward motion (236 from north) of $22 \mathrm{~mm} / \mathrm{yr}$ relative to a hotspot reference frame. Flow in the 


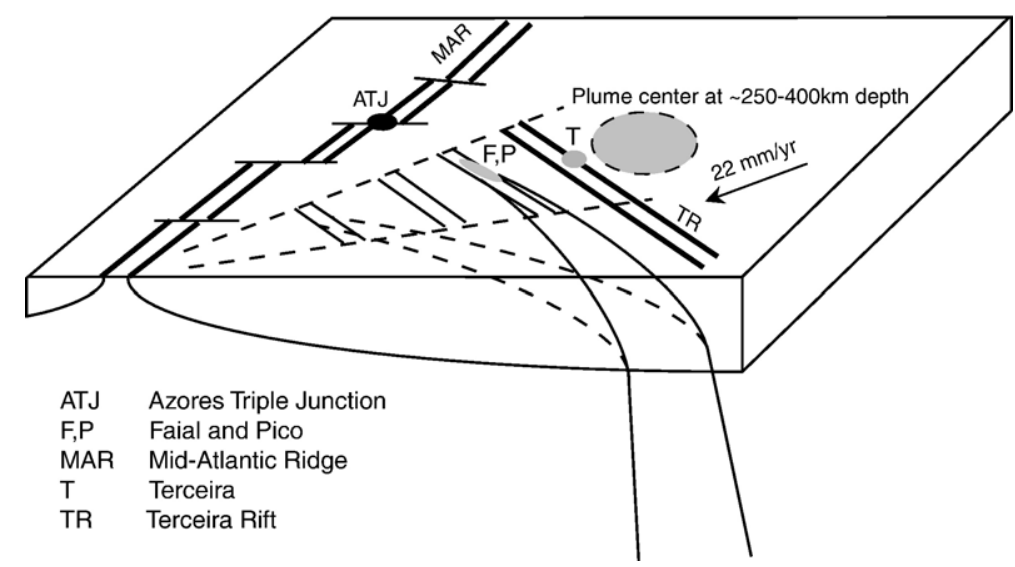

Fig. 9. Schematic view of the proposed hotspot-ridge interaction model for the Azores region, showing the location of the Mid-Atlantic Ridge (MAR), Terceira Rift (TR), Azores Triple Junction (ATJ), the islands of Terceira (T), Faial (F), and Pico (P), and the projected surface location of the center of plume upwelling center at $\sim 250-400 \mathrm{~km}$ depth. Lines parallel to the Terceira Rift represent possible locations of failed rifts associated with the migration of the triple junction from the Pico Fracture Zone to its present location. The dashed lines bounding these parallel lines approximately outline the bathymetric high between the Pico Fracture Zone and the present hotspot location. The arrow shows the direction of absolute motion of the African and Eurasian plates near the Azores relative to a hotspot reference frame [53].

asthenosphere driven by plate motion or by plate motion plus the effect of 3-D density heterogeneity in the mantle is also predicted to be in the southwestern direction beneath the Azores [54]. By this explanation, the mantle plume is deflected horizontally by the (net southwestward) upper mantle flow driven at least in part by the absolute plate motion. Hot upwelling plume material feeds preferentially toward the southwest instead of dispersing radially. A schematic illustration of the main features of the Azores hotspot and our geodynamic interpretation of the observed velocity anomalies is shown in Fig. 9.

The inference that the root of the hotspot is located northeast of Terceira is consistent with geochemical observations. While the youngest maximum ages of basalts on individual islands are found at Faial, Pico, and Sao Jorge, Moreira et al. [5] and Madureira et al. [55] suggested that the center of the plume is located near Terceira because the highest ${ }^{3} \mathrm{He} /{ }^{4} \mathrm{He}$ and ${ }^{20} \mathrm{Ne} /{ }^{22} \mathrm{Ne}$ ratios are found at this island. Modeling of U-series systematics from the Azores Islands and the nearby MAR also suggests a relatively higher upwelling velocity near Terceira (30-40 mm/yr) than for surrounding areas [56]. Upwelling northeast of Terceira could bring relatively enriched, undegased compositions to shallower depths. As the upwelling plume conduit is tilted to the southwest by mantle shear flow, volatiles and other incompatible elements, including helium and neon, would preferentially enter into melt formed during the early stages of melting near Terceira. These deeply generated melts could be tapped by the leaky Terceira Rift to form Terceira. Further buoyant rise and de- compression melting would generate isotopically less anomalous basalts at Faial, Pico, and Sao Jorge. This geochemical pattern is similar to what has been observed elsewhere, e.g., correlated helium and neon anomalies at the East Pacific Rise near $17^{\circ} \mathrm{S}$, interpreted to be the result of a tilted mantle heterogeneity [57], and the off-axis gradients in isotope ratios along the Salas y Gomez hotspot near the East Pacific Rise [58,59].

The interpretation of our tomographic model helps to reconcile the apparent paradox that Terceira has the highest geochemical anomalies (e.g., helium) among the islands, whereas the peak of geochemical anomalies along the MAR near the Azores is located near $39^{\circ} \mathrm{N}$, close to Pico, Faial, and Sao Jorge (Fig. 1). In the mantle-plume source to migrating-ridge sink (MPS/ MRS) model proposed by Schilling [60], the migrating ridge is fed by preferential plume flow along a thermally induced channel at the base of the lithosphere. Laboratory [61] and numerical experiments [62,63] have demonstrated that the presence of a sloping rheological boundary layer (RBL) that thickens away from the ridge axis can favor the formation of a sublithospheric channel perpendicular to the ridge axis, through which an off-axis plume can feed hot material and melt to the ridge. In the model of Fig. 9, plume flow does not feed the MAR north of Terceira through a channel perpendicular to the ridge axis, but instead the "exit" point of the upwelling flux beneath the lithosphere is located southwest of Terceira, near Pico, Faial, and Sao Jorge. Taking the geochemical observations along the MAR into consideration, we suggest that plume material subsequently flows westward to the 
MAR along the sloping RBL. Although there is a lowamplitude low-velocity anomaly between the MAR and the center of the plateau at about $200 \mathrm{~km}$ depth (Fig. 6) and resolution tests indicate a marginal ability to detect such an anomaly, we caution that sampling in the shallow mantle near the ridge axis is poor because of the large station spacing across the MAR (Fig. 5). Thus we cannot distinguish between flow of plume material in a pipe-like channel toward the ridge [64] and broad, pancake-like gravity currents $[59,65,66]$. A seafloor seismic experiment would be required to resolve this question.

\subsection{Asymmetry in the influence of the hotspot on the $M A R$}

The time-transgressive, $\mathrm{V}$-shaped ridge bathymetric features (Fig. 1) and geochemical gradients along the MAR south of the Azores suggest a flow of plume material dispersed preferentially southwestward along the ridge $[1,2,67,68]$. The large-amplitude, shortwavelength anomalies in geochemistry and bathymetry south of the Azores likely reflect temporal variations in the flux of plume material to the ridge [7]. It is noteworthy that there is an east-west asymmetry in the $\mathrm{V}$-shaped ridges. The band of high bathymetry connecting the proposed center of the plume and the Pico Fracture Zone is more pronounced than the bathymetric anomaly on the western flank of the MAR. This eastwest asymmetry in the $\mathrm{V}$-shaped ridges may be attributable to the surface manifestation of sublithospheric flow between the plume and the MAR.

While V-shaped bathymetric highs extend southwestward along the MAR as far south as $27^{\circ} \mathrm{N}[6,8]$, such features are not observed on the ridge flanks north of the Azores. Geophysical anomalies including topography, crustal structure, and thermal structure associated with the hotspot disappear northward of $43^{\circ} \mathrm{N}$ [69]. Several geochemical signatures show a similar asymmetric pattern $[1,4,7]$. These features indicate a weak mantle plume influence along the ridge north of the Azores.

\subsection{Triple junction jump}

It is widely accepted that, starting from $\sim 36 \mathrm{Ma}$, the Azores triple junction (ATJ) moved from the intersection of the MAR and the East Azores Fracture Zone (EAFZ) northward to its present location (believed to be $38.55^{\circ} \mathrm{N}, 30.0^{\circ} \mathrm{W}$ [10], Fig. 1) and changed type from ridge-fault-fault (RFF) to ridge-ridge-ridge (RRR) or ridge-ridge-leaky transform $[9,10,70,71]$. The cause of neither the ATJ jump nor the change in triple junction type, however, is clear. Previous analyses focused mainly on plate kinematics, seafloor topography, and magnetic signature. For example, Searle [9] argued that the reversal in the relative motion between the Eurasian and African plates produced a component of extension across the old EAFZ from 53-36 Ma, and this extension led to the initiation of the Terceira Rift. This scenario does not explain, however, the evolution of the plate boundary from the EAFZ to the current Terceira Rift. The possible presence of a mantle plume beneath the area surrounding this triple junction has not been incorporated in prior models for the evolution of the ATJ.

Schilling [60] pointed out that near-ridge plumes can have important dynamic and tectonic effects on nearby spreading centers, including the generation of propagating rifts [72], the development of transient microplates [64], the induction of ridge jumps toward the plume, and as a result, the generation of large transform-fault offsets. The lateral flow of hot plume material beneath the base of the lithosphere could serve to weaken the lithosphere, generate a new rift [73], and cause the sink of the plume flow to relocate toward the hotspot [60]. This mechanism has been proposed to explain the evolution of several near-ridge hotspots such as Iceland [74,75], Louisville, and Shano [73].

The evolution of the ATJ can be explained by a similar scenario. As the African and Eurasian plates move southwestward in the hotspot reference frame, hot upwelling mantle centered northeast of Terceira may weaken the overlying lithosphere. Together with possible temporal variations in plate boundary stresses [9], this effect may lead to a new rift between the plume center and the previous rift, causing the relocation of the triple junction northward toward the center of the plume. This process might have occurred in stages. Bathymetric ridges having the same orientation as the Terceira Rift cross the MAR high on the spreading center's eastern flank (Fig. 1); these ridges were presumably not generated at the MAR because they are not observed on the western flank. Likely they are failed rifts, the previous sinks of the mantle flow. One consequence of this northward jump of the African-Eurasian plate boundary is that the flux of plume material feeding the southwestern portion of the MAR would abate during the ATJ jump, because part of the buoyant material would have been transferred to fill the newly formed rift. It has been suggested that variation in the supply of melt accounts for many of the discontinuities in V-shaped ridges south of the Azores compared with the situation on the Reykjanes Ridge [8]. 


\subsection{Radius of plume conduit and mantle rheology}

At $300-375 \mathrm{~km}$ depth, the radius of the cylindrical low-velocity anomaly northeast of Terceira (defined as the total width at half the maximum magnitude of the anomaly) is $\sim 100 \mathrm{~km}$. The apparent radius and magnitude of the velocity anomaly should be considered upper and lower bounds, respectively, because damping, finite grid spacing, and streaking in the tomographic inversion tend to broaden the true anomaly and reduce its magnitude. In a resolution test having a Gaussianshaped, vertical cylindrical velocity anomaly with a half width of $100 \mathrm{~km}$, the recovered half width in the inversion is $\sim 25 \%$ larger. For comparison, the radius of the low-velocity anomaly (also defined as the total width at half the maximum magnitude of the anomaly) at the same depth interval beneath Iceland is $170 \mathrm{~km}$ [21]. From simulated waveforms propagating through several tomographic models of the Iceland hotspot, Allen and Tromp [76] found that the radius of the upwelling conduit beneath Iceland (defined as the half width of a Gaussian-shaped velocity anomaly) must be in the range 50 to $100 \mathrm{~km}$.

With the limitations of tomographic resolution in mind, it is nonetheless useful to explore the constraints provided by the tomographic model on mantle dynamics in the vicinity of the hotspot. We focus the analyses at $300-375 \mathrm{~km}$ depth to minimize the possible presence of partial melt and the effect of crustal heterogeneity. When the effects of anelasticity are taken into consideration (Eq. (13b) in Karato [77], with a background $Q_{\mathrm{P}}$ of $200-300$ at $300-375 \mathrm{~km}$ depth $[78,79]$, a background temperature $T_{0}=1600 \mathrm{~K}$, $\alpha=0.23$, and other parameters as in Karato [77]), the peak $P$-velocity reduction beneath the Azores $(-2.0 \%)$ is equivalent to $190-220 \mathrm{~K}$ effective excess temperature $\left(\Delta T_{\text {eff }}\right)$. About half of the effective excess temperature inferred from the velocity reduction can be attributed to the anomalously high water content in the Azores hotspot source. A factor of 5-10 times more water in the mantle source beneath the Azores compared with the source of normal mid-ocean ridge basalt (NMORB) [80] increases the effective temperature by $\Delta T_{\mathrm{w}}=100-120 \mathrm{~K}$ [77], so the actual temperature anomaly is about $70-120 \mathrm{~K}\left(\Delta T=\Delta T_{\text {eff }}\right.$ $\left.-\Delta T_{\mathrm{w}}\right)$. For comparison, geochemical and other geophysical estimates of the excess temperature of the Azores mantle plume vary from $200 \mathrm{~K}$ [60] to $55 \mathrm{~K}$ along the MAR near the Azores [80], where the lower value takes into account the effect of the anomalously high water content in the mantle source on melting behavior. The apparent agreement in the estimates of the excess temperature is probably fortuitous, because resolution tests indicate that the recovered anomaly is significantly less than the input anomaly. This issue could be reconciled if the magnitude of the true anomaly is greater than $2.0 \%$ but the unrecovered portion of the true anomaly arises from factors not included in the above calculations (e.g., melt).

The observation of a lateral shift of the lowvelocity anomaly with depth beneath the Azores has important implications for the rheology of the oceanic upper mantle. From experimental simulations of a plume tilted in large-scale flow, Richards and Griffths [51] obtained a modified Stokes formula for the rising speed of a plume conduit through the surrounding viscous mantle:

$v_{\mathrm{c}}=\frac{0.54 \Delta \rho g r_{\mathrm{c}}^{2}}{\eta_{\text {out }}}$

where $\Delta \rho$ is the density contrast between the plume and surrounding material, $g$ is gravitational acceleration, $r_{\mathrm{c}}$ is the conduit radius, and $\eta_{\text {out }}$ is the viscosity of the surrounding mantle. We note that the conduit rising speed $v_{\mathrm{c}}$ is not to be confused with the velocity of material upwelling through the conduit [52]. The factor 0.54 was determined experimentally for a "chemical" plume with different materials inside and outside the conduit. This formula serves as a firstorder approximation for a thermal plume for which thermal entrainment of surrounding mantle may be important. A simple shear flow with a linear velocity profile through an upper mantle shear zone, such as flow driven by the motion of a plate over a uniformviscosity upper mantle, gives rise to a parabolic depth profile for the conduit, with bending in the direction of shear flow. The amount of lateral shift of the plume conduit from a fixed source in the deep mantle to the exit point at the surface, $x_{\text {offset, follows the }}$ relationship:

$x_{\text {offset }}=0.5 \frac{u_{0}}{v_{\mathrm{c}}} d$

where $u_{0}$ is the plate velocity in the hotspot reference frame and $d$ is the depth to the plume source over which shearing occurs [51,52]. With $x_{\text {offset }}=200 \mathrm{~km}$ (Fig. 6), $d=250-300 \mathrm{~km}$, and $u_{0}=22 \mathrm{~mm} / \mathrm{yr}$, Eq. (3) gives $v_{\mathrm{c}}=15-17 \mathrm{~mm} / \mathrm{yr}$ for the rising velocity of the conduit. We note that the tilt of the lower part of the conduit is expected to be smaller than that of the upper part because of the parabolic profile of the conduit with depth. We cannot exclude the possibility of a 
small tilt at $300-400 \mathrm{~km}$ depth. For a uniform upper mantle viscosity and $d=400 \mathrm{~km}$, the rising velocity $v_{\mathrm{c}}$ equals $22 \mathrm{~mm} / \mathrm{yr}$.

Assuming that the density contrast $\Delta \rho$ is caused primarily by the excess temperature of the plume (i.e., $\Delta \rho=\alpha \Delta \bar{T} \rho$, where $\alpha=3 \times 10^{-5} \mathrm{~K}^{-1}, \rho=3400 \mathrm{~kg} \mathrm{~m}^{-3}$, and an average temperature anomaly of $\Delta \bar{T}=50 \pm 25 \mathrm{~K}$ within a conduit of radius $100 \pm 25 \mathrm{~km}$ ) and substituting $v_{\mathrm{c}}$ into Eq. (2), we obtain $\eta_{\text {out }}=(1-8) \times 10^{20} \mathrm{~Pa} \mathrm{~s}$, in good agreement with estimates of upper mantle viscosity from glacial rebound $\left(4 \times 10^{20} \mathrm{~Pa} \mathrm{~s}\right)$ [81].

Following Olson et al. [82] and Korenaga [83], we define the buoyancy flux of a steady-state, buoyancydriven upwelling through a circular conduit as

$\dot{M}=\frac{\pi\left(\alpha \rho \Delta T_{\mathrm{c}}\right)^{2} g a^{4}}{A \eta_{\mathrm{c}}}$

where $\eta_{\mathrm{c}}$ is the centerline plume viscosity, $\Delta T_{\mathrm{c}}$ is the centerline plume temperature anomaly, and $a$ is the conduit radius, defined here as the radius where the temperature anomaly is one-half its centerline value ( $a$ is approximately equal to the half width at half the maximum magnitude of the velocity anomaly). The constant $A$ is equal to $\left(\log \left(\eta_{\text {out }} / \eta_{\mathrm{c}}\right)\right)^{2}$. From an estimated buoyancy flux of the Azores hotspot of $1.1 \times 10^{3} \mathrm{~kg} \mathrm{~s}^{-1}$ [84] and $\Delta T_{\mathrm{c}}=100 \pm 50 \mathrm{~K}, \eta_{\mathrm{c}}=4 \times 10^{18} \mathrm{~Pa}$ s. If the radius of the plume conduit inferred from tomography is overestimated by $25 \%$ as the resolution tests indicate, the viscosity at the center of the plume $\eta_{\mathrm{c}}$ could be lower by a factor of 10 .

\section{Conclusions}

Despite the limitations of the seismic data set from the Azores, finite-frequency seismic tomography utilizing 3-D sensitivity kernels provides important constraints on the characteristics of the Azores hotspot and the nearby Mid-Atlantic Ridge. There is a lowvelocity anomaly in the shallow mantle (less than $250 \mathrm{~km}$ depth) along the Azores Islands and beneath the center of the Azores Plateau $\left(38.5^{\circ} \mathrm{N}, 28.5^{\circ} \mathrm{W}\right)$. This anomaly connects downward and northeastward to a columnar low-velocity anomaly centered northeast of Terceira and extending from $\sim 250 \mathrm{~km}$ depth to at least the top of the transition zone. We infer that this columnar low-velocity body marks the locus of the Azores plume and that this plume is sheared southwestward as it rises through the uppermost mantle. The bending of the plume conduit and the preferential supply of plume material toward the southwest beneath the Azores are consistent with other geophy- sical and geochemical observations. This Azores hotspot model provides an explanation for the asymmetry in hotspot influence on the MAR to the south and north of the Azores as well as the evolution in the location of the triple junction between the North American, Eurasian, and African plates.

\section{Acknowledgements}

We thank all participants of the COSEA experiment and four anonymous reviewers for their constructive comments. Financial support for this study was provided by the National Science Foundation under grant OCE-0425747 and by the Carnegie Institution of Washington.

\section{References}

[1] J.-G. Schilling, Azores mantle blob: rare-earth evidence, Earth Planet. Sci. Lett. 25 (1975) 103-115.

[2] J.-G. Schilling, M. Zajac, R. Evans, T. Johnston, W. White, J.D. Devine, R. Kingsley, Petrologic and geochemical variations along the Mid-Atlantic Ridge from $29^{\circ} \mathrm{N}$ to $73^{\circ}$, Am. J. Sci. 283 (1983) 510-586.

[3] R.H. Kingsley, J.-G. Schilling, Carbon in Mid-Atlantic Ridge basalt glasses from $28^{\circ} \mathrm{N}$ to $63^{\circ} \mathrm{N}$ : evidence for a carbon-enriched Azores mantle plume, Earth Planet. Sci. Lett. 129 (1995) 31-53.

[4] D. Yu, D. Fontignie, J.-G. Schilling, Mantle plume - ridge interactions in the Central North Atlantic: a Nd isotope study of Mid-Atlantic Ridge basalts from $30^{\circ} \mathrm{N}$ to $50^{\circ}$, Earth Planet. Sci. Lett. 146 (1997) 259-272.

[5] M. Moreira, R. Doucelance, M.D. Kurz, B. Dupré, C.J. Allègre, Helium and lead isotope geochemistry of the Azores archipelago, Earth Planet. Sci. Lett. 169 (1999) 189-205.

[6] R. Thibaud, P. Gente, M. Maia, A systematic analysis of the MidAtlantic Ridge morphology and gravity between $15^{\circ} \mathrm{N}$ and $40^{\circ} \mathrm{N}$ : constraints of the thermal structure, J. Geophys. Res. 103 (1998) 24223-24243.

[7] J. Goslin, J.-L. Thirot, O. Noël, J. Francheteau, Slow-ridge/ hotspot interactions from global gravity, seismic tomography and ${ }^{87} \mathrm{Sr} /{ }^{86} \mathrm{Sr}$ isotope data, Geophys. J. Int. 135 (1998) 700-710.

[8] J. Escartín, M. Cannat, G. Pouliquen, A. Rabain, J. Lin, Crustal thickness of V-shaped ridges south of the Azores: interaction of the Mid-Atlantic Ridge $\left(36^{\circ}-39^{\circ} \mathrm{N}\right)$ and the Azores hot spot, J. Geophys. Res. 106 (2001) 21719-21735.

[9] R. Searle, Tectonic pattern of the Azores spreading centre and triple junction, Earth Planet. Sci. Lett. 51 (1980) 415-434.

[10] J. Freire Luis, J.M. Miranda, A. Galdeano, P. Patriat, J.C. Rossignol, L.A. Mendes Victor, The Azores triple junction evolution since $10 \mathrm{Ma}$ from an aeromagnetic survey of the MidAtlantic Ridge, Earth Planet. Sci. Lett. 125 (1994) 439-459.

[11] Y.-S. Zhang, T. Tanimoto, High-resolution global upper mantle structure and plate tectonics, J. Geophys. Res. 98 (1993) 9793-9823.

[12] R. Montelli, G. Nolet, F.A. Dahlen, G. Masters, E.R. Engdahl, S.-H. Hung, Finite-frequency tomography reveals a variety of plumes in the mantle, Science 303 (2004) 338-343.

[13] G. Silveira, E. Stutzmann, D.-A. Griot, J.-P. Montagner, L. Mendes Victor, Anisotropic tomography of the Atlantic 
Ocean from Rayleigh surface waves, Phys. Earth Planet. Inter. 106 (1998) 257-273.

[14] G. Silveira, E. Stutzmann, Anisotropic tomography of the Atlantic Ocean, Phys. Earth Planet. Inter. 132 (2002) 237-248.

[15] F. Marone, S. Van der Lee, D. Giardini, Three-dimensional upper mantle S-velocity model for the Eurasia-Africa plate boundary region, Geophys. J. Int. 158 (2004) 109-130.

[16] S. Pilidou, K. Priestley, Ó. Gudmundsson, E. Debayle, Upper mantle S-wave speed heterogeneity and anisotropy beneath the North Atlantic from regional surface wave tomography: the Iceland and Azores plumes, Geophys. J. Int. 159 (2004) 1057-1076.

[17] H.-C. Nataf, Seismic imaging of mantle plumes, Annu. Rev. Earth Planet. Sci. 28 (2000) 391-417.

[18] C.J. Wolfe, I.Th. Bjarnason, J.C. VanDecar, S.C. Solomon, Seismic structure of the Iceland mantle plume, Nature 385 (1997) $245-247$.

[19] G.R. Foulger, M.J. Pritchard, B.R. Julian, J.R. Evans, R.M. Allen, G. Nolet, W.J. Morgan, B.H. Bergsson, P. Erlendsson, S. Jakobsdottir, S. Ragnarsson, R. Stefansson, K. Vogfjörd, Seismic tomography shows that upwelling beneath Iceland is confined to the upper mantle, Geophys. J. Int. 146 (2001) 504-530.

[20] R.M. Allen, G. Nolet, W.J. Morgan, K. Vogfjörd, B.H. Bergsson, P. Erlendsson, G.R. Foulger, S. Jakobsdóttir, B.R. Julian, M. Pritchard, S. Ragnarsson, R. Stefánsson, Imaging the mantle beneath Iceland using integrated seismological techniques, J. Geophys. Res. 107 (B12) (2002) 2325, doi:10.1019/ 2001JB000595.

[21] S.-H. Hung, Y. Shen, L.-Y. Chiao, Imaging seismic velocity structure beneath the Iceland hot spot: a finite frequency approach, J. Geophys. Res. 109 (B8) (2004) B08305, doi:10.1029/2003JB002889.

[22] Y. Shen, S.-H. Hung, Ridge-like upwelling in the uppermost lower mantle beneath eastern Africa from finite-frequency seismic tomography, Eos Trans. Am. Geophys. Union 85 (47) (2004) Fall Meeting Suppl., Abstract U41A-0720.

[23] G. Silveira, S. van der Lee, E. Stutzmann, L. Matias, D. James, P. Burkett, M. Miranda, L. Mendes Victor, J.L. Gaspar, L. Senos, S. Solomon, J.-P. Montagner, D. Giardini, Coordinated seismic experiment in the Azores, ORFEUS Newsl. 4 (2) (2002) 10.

[24] S.C. Webb, Broadband seismology and noise under the ocean, Rev. Geophys. 36 (1998) 105-142.

[25] J.C. VanDecar, R.S. Crosson, Determination of teleseismic relative phase arrival times using multi-channel cross-correlation and least squares, Bull. Seismol. Soc. Am. 80 (1990) $150-169$.

[26] K. Aki, A. Christoffersson, E.S. Husebye, Determination of the three-dimensional seismic structure of the lithosphere, J. Geophys. Res. 82 (1977) 277-296.

[27] A.M. Dziewonski, Mapping the lower mantle: determination of lateral heterogeneity in $\mathrm{P}$ velocity up to degree and order 6, J. Geophys. Res. 89 (1984) 5929-5952.

[28] S.P. Grand, Mantle shear structure beneath the Americas and surrounding oceans, J. Geophys. Res. 99 (1994) 11591-11621.

[29] R.D. Van der Hilst, S. Widiyantoro, E.R. Engdahl, Evidence for deep mantle circulation from global tomography, Nature 386 (1997) 578-584.

[30] D. Zhao, Seismic structure and origin of hotspots and mantle plumes, Earth Planet. Sci. Lett. 192 (2001) 251-265.

[31] G. Nolet, F.A. Dahlen, Wave front healing and the evolution of seismic delay times, J. Geophys. Res. 105 (2000) 19043-19054.
[32] S.-H. Hung, F.A. Dahlen, G. Nolet, Wavefront healing: a banana-doughnut perspective, Geophys. J. Int. 146 (2001) 289-312.

[33] A.M. Baig, F.A. Dahlen, S.-H. Hung, Traveltimes of waves in three-dimensional random media, Geophys. J. Int. 153 (2003) 467-482.

[34] H. Marquering, F.A. Dahlen, G. Nolet, Three-dimensional sensitivity kernels for finite-frequency traveltimes: the banana-doughnut paradox, Geophys. J. Int. 137 (1999) 805-815.

[35] F.A. Dahlen, S.-H. Hung, G. Nolet, Fréchet kernels for finite frequency traveltimes: I. Theory, Geophys. J. Int. 141 (2000) $157-174$.

[36] L. Zhao, T.H. Jordan, C.H. Chapman, Three-dimensional Fréchet differential kernels for seismic delay times, Geophys. J. Int. 141 (2000) 558-576.

[37] H.-Y. Yang, S.-H. Hung, Validation of ray and wave theoretical travel times in heterogeneous random media, Geophys. Res. Lett. 32 (2005) L20302, doi:10.1029/2005GL023501.

[38] S.-H. Hung, F.A. Dahlen, G. Nolet, Fréchet kernels for finitefrequency traveltimes: II. Examples, Geophys. J. Int. 141 (2000) 175-203.

[39] L.-Y. Chiao, B.-Y. Kuo, Multiscale seismic tomography, Geophys. J. Int. 145 (2001) 517-527.

[40] C.C. Paige, M.A. Saunders, LSQR: an algorithm for sparse linear equations and sparse least squares, ACM Trans. Math. Softw. 8 (1982) 43-71.

[41] W. Menke, Geophysical Data Analysis: Discrete Inverse Theory, rev. ed., Academic Press, San Diego, Calif., 1989. 285 pp.

[42] W.R. Keller, D.L. Anderson, R.W. Clayton, Resolution of tomographic models of the mantle beneath Iceland, Geophys. Res. Lett. 27 (2000) 3993-3996.

[43] C.J. Wolfe, I.Th. Bjarnason, J.C. VanDecar, S.C. Solomon, Assessing the depth resolution of tomographic models of upper mantle structure beneath Iceland, Geophys. Res. Lett. 29 (2002) 1015, doi:10.1029/20001GL013657.

[44] F. Marone, M. van der Meijde, S. van der Lee, D. Giardini, Joint inversion of local, regional and teleseismic data for crustal thickness in the Eurasia-Africa plate boundary region, Geophys. J. Int. 154 (2003) 499-514.

[45] K.E. Louden, B.E. Tucholke, G.N. Oakey, Regional anomalies of sediment thickness, basement depth and isostatic crustal thickness in the North Atlantic Ocean, Earth Planet. Sci. Lett. 224 (2004) 193-211.

[46] G. Feraud, I. Kaneoka, C.J. Allègre, K/Ar ages and stress pattern in the Azores: geodynamic implications, Earth Planet. Sci. Lett. 46 (1980) 275-286.

[47] J. Madeira, A. Ribeiro, Geodynamic models for the Azores triple junction: a contribution from tectonics, Tectonophysics 184 (1990) 405-415.

[48] Y. Shen, S.C. Solomon, I.Th. Bjarnason, C.J. Wolfe, Seismic evidence for a lower-mantle origin of the Iceland plume, Nature 395 (1998) 62-65.

[49] X. Li, R. Kind, K. Priestley, S.V. Sobolev, F. Tilmann, X. Yuan, M. Weber, Mapping the Hawaiian plume conduit with converted seismic waves, Nature 405 (2000) 938-941.

[50] X. Li, R. Kind, X. Yuan, Seismic study of upper mantle and transition zone beneath hotspots, Phys. Earth Planet. Inter. 136 (2003) 79-92.

[51] M.A. Richards, R.W. Griffiths, Deflection of plumes by mantle shear flow: experimental results and a simple theory, Geophys. J. 94 (1988) 367-376. 
[52] B. Steinberger, R.J. O'Connell, Effects of mantle flow on hotspot motion, in: M.A. Richards, R.G. Gordon, R.D. van der Hilst (Eds.), The History and Dynamics of Global Plate Motions, Geophysical Monograph Series, vol. 121, Am. Geophys. Union, Washington, DC, 2000, pp. 377-398.

[53] A.E. Gripp, R.G. Gordon, Young tracks of hotspots and current plate velocities, Geophys. J. Int. 150 (2002) 321-361.

[54] M.D. Behn, C.P. Conrad, P.G. Silver, Detection of upper mantle flow associated with the African Superplume, Earth Planet. Sci. Lett. 224 (2004) 259-274.

[55] P. Madureira, M. Moreira, J. Mata, C.J. Allègre, Primitive neon isotopes in Terceira Island (Azores archipelago), Earth Planet. Sci. Lett. 233 (2005) 429-440.

[56] B. Bourdon, S.P. Turner, N.M. Ribe, Partial melting and upwelling rates beneath the Azores from a U-series isotope perspective, Earth Planet. Sci. Lett. 239 (2005) 42-56.

[57] M.D. Kurz, M. Moreira, J. Curtice, D.E. Lott III, J.J. Mahoney, J.M. Sinton, Correlated helium, neon, and melt production on the super-fast spreading East Pacific Rise near $17^{\circ} \mathrm{S}$, Earth Planet. Sci. Lett. 232 (2005) 125-142.

[58] R.H. Kingsley, J.-G. Schilling, J.E. Dixon, P. Swart, R. Poreda, K. Simons, D/H ratios in basalt glasses from the Salas y Gomez mantle plume interacting with the East Pacific Rise: water from old D-rich recycled crust or primordial water from the lower mantle? Geochem. Geophys. Geosyst. 3 (4) (2002) 1025, doi: $10.1029 / 2001 \mathrm{GC} 000199$.

[59] P.S. Hall, C. Kincaid, Melting, dehydration, and the geochemistry of off-axis plume-ridge interaction, Geochem. Geophys. Geosyst. 5 (2004) Q12E18, doi:10.1029/2003GC000667.

[60] J.-G. Schilling, Fluxes and excess temperature of mantle plumes inferred from their interaction with migrating mid-ocean ridges, Nature 352 (1991) 397-403.

[61] C. Kincaid, G. Ito, C. Gable, Laboratory investigation of the interaction of off-axis mantle plumes and spreading centres, Nature 376 (1995) 758-761.

[62] C. Kincaid, J.-G. Schilling, C. Gable, The dynamics of off-axis plume-ridge interaction in the uppermost mantle, Earth Planet. Sci. Lett. 137 (1996) 29-43.

[63] P.S. Hall, C. Kincaid, Melting, dehydration, and the dynamics of off-axis plume-ridge interaction, Geochem. Geophys. Geosyst. 4 (9) (2003) 8510, doi:10.1029/2003GC000567.

[64] J.-G. Schilling, H. Sigurdsson, A.N. Davis, R.N. Hey, Easter microplate evolution, Nature 317 (1985) 325-331.

[65] N.M. Ribe, The dynamics of plume-ridge interaction, 2. Offridge plumes, J. Geophys. Res. 101 (1996) 16195-16204.

[66] G. Ito, J. Lin, D. Graham, Observational and theoretical studies of the dynamics of mantle plume-mid-ocean ridge interaction, Rev. Geophys. 41 (4) (2003) 1017, doi:10.1029/2002RG000117.

[67] W.M. White, J.-G. Schilling, The nature and origin of geochemical variation in Mid-Atlantic Ridge basalts from the Central North Atlantic, Geochim. Cosmochim. Acta 42 (1978) $1501-1516$
[68] C.G. Chase, Asthenospheric counterflow: a kinematic model, Geophys. J. R. Astron. Soc. 56 (1979) 1-18.

[69] J. Goslin, Triatnord Scientific Party, Extent of Azores plume influence on the Mid-Atlantic Ridge north of the hotspot, Geology 27 (1999) 991-994.

[70] D.C. Krause, N.D. Watkins, North Atlantic crustal genesis in the vicinity of the Azores, Geophys. J. R. Astron. Soc. 19 (1970) 261-283.

[71] D. McKenzie, Active tectonics of the Mediterranean region, Geophys. J. R. Astron. Soc. 30 (1972) 109-185.

[72] J.-G. Schilling, R.H. Kingsley, J.D. Devine, Galapagos hot spotspreading center system, 1 . Spatial petrological and geochemical variations $\left(83^{\circ} \mathrm{W}-101^{\circ} \mathrm{W}\right)$, J. Geophys. Res. 87 (1982) 5593-5610.

[73] C. Small, Observations of ridge-hotspot interactions in the Southern Ocean, J. Geophys. Res. 100 (1995) 17931-17946.

[74] J. Helgason, Shifts of the plate boundary in Iceland: some aspects of Tertiary volcanism, J. Geophys. Res. 90 (1985) 10084-10092.

[75] B.S. Hardarson, J.G. Fitton, R.M. Ellam, M.S. Pringle, Rift relocation - a geochemical and geochronological investigation of a paleo-rift in northwest Iceland, Earth Planet. Sci. Lett. 153 (1997) 181-196.

[76] R.M. Allen, J. Tromp, Resolution of regional seismic models: squeezing the Iceland anomaly, Geophys. J. Int. 161 (2005) 373-386

[77] S. Karato, Mapping water content in the upper mantle, in: J. Eiler (Ed.), Inside the Subduction Factory, Geophysical Monograph Series, vol. 138, Am. Geophys. Union, Washington, DC, 2003, pp. 135-152.

[78] Y. Gung, B. Romanowicz, Q tomography of the upper mantle using three-component long-period waveforms, Geophys. J. Int 157 (2004) 813-830.

[79] M.E. Wysession, J.F. Lawrence, Imaging the East Asian lower mantle water anomaly, Eos Trans. Am. Geophys. Union 86 (52) (2005) Fall Meeting Suppl., Abstract MR44A-06.

[80] P.D. Asimow, C.H. Langmuir, The importance of water to oceanic mantle melting regimes, Nature 421 (2003) 815-820.

[81] K. Lambeck, P. Johnston, The viscosity of the mantle: evidence from analyses of glacial-rebound phenomena, in: I. Jackson (Ed.), The Earth's Mantle: Composition, Structure, and Evolution, Cambridge University Press, Cambridge, 1998, pp. 461-502.

[82] P. Olson, G. Schubert, C. Anderson, Structure of axisymmetric mantle plumes, J. Geophys. Res. 98 (1993) 6829-6844.

[83] J. Korenaga, Firm mantle plumes and the nature of the coremantle boundary region, Earth Planet. Sci. Lett. 232 (2005) 29-37.

[84] N.H. Sleep, Hotspots and mantle plumes: some phenomenology, J. Geophys. Res. 95 (1990) 6715-6736.

[85] B.L.N. Kennett, E.R. Engdahl, Traveltimes for global earthquake location and phase identification, Geophys. J. Int. 105 (1991) 429-465. 